\title{
Exposure to physical and sexual violence and suicidal ideation among schoolchildren
}

\author{
Exposição à violência física e sexual e ideação suicida entre escolares \\ Julia Luiza Schäfer', Vanessa Andina Teixeira², Larissa Prado da Fontoura³ ${ }^{3}$ Luís César de Castro4, \\ Rogério Lessa Horta²
}

\section{ABSTRACT}

Objective: The purpose of this study was to estimate the association between exposure to physical and sexual violence, and suicidal ideation in Brazilian Schoolchildren, accounting for confounding variables of religious practice, and problems with alcohol and other drugs.

Methods: This study consists of a cross-sectional analytical approach of a larger school-based study conducted in 2012 in two medium-sized municipalities in south of Brazil. Participants were 3,547 students aging 12 to 17 years old who answered an assembled questionnaire. Descriptive and Logistic Regression analyses were conducted with suicide ideation outcome testing prediction models stratified by sex. Results: Suicide ideation prevalence in the sample was of $21.7 \%$, and regression analysis indicated that girls and boys exposed to physical or sexual violence had 3.42 and 3.14 times more probability of referring suicidal ideation in the past 30 days. Adjusted analyses showed little interference of religious practice, while problems with alcohol and other drugs seemed to also explain suicidal ideation in the sample.

\section{Keywords}

Suicidal ideation, adolescent behavior, child abuse.
Conclusion: We highlight the importance of future longitudinal studies to investigate the mechanisms through which exposure to physical or sexual abuse influence suicidal ideation among boys and girls, as well as mediation studies that could enlighten the role of drug and alcohol use in this relationship.

\section{RESUMO}

Objetivo: O objetivo deste estudo foi estimar a associação entre exposição à violência física e sexual e ideação suicida em escolares brasileiros, controlando para variáveis relacionadas a prática religiosa e problemas com álcool e outras drogas. Métodos: Este estudo consiste de um recorte transversal de um estudo maior realizado em 2012 em dois municípios de médio porte no sul do Brasil. No total, 3.547 alunos de 12 a 17 anos responderam a um questionário desenvolvido para o estudo em questão. Análises descritivas e de regressão logística foram conduzidas testando modelos preditores de ideação suicida estratrificados por sexo. Resultados: A prevalência de ideação suicida na amostra foi de $21,7 \%$ e a análise de regressão indicou que meninas e meninos expostos à violência física ou sexual tinham 3,42 e 3,14 vezes mais probabilidade de referir ideação suicida nos últimos 30 dias. As análises ajustadas mostraram pouca interferência da prática religiosa, enquanto problemas com álcool e outras

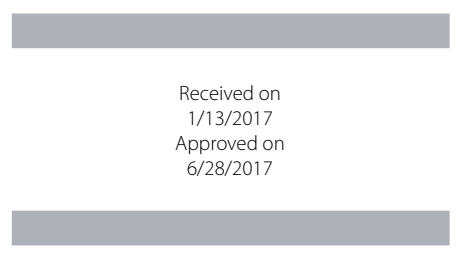

DOI: 10.1590/0047-20850000000156
1 Pontifícia Universidade Católica do Rio Grande do Sul (PUC-RS). 2 Universidade do Vale do Rio dos Sinos (Unisinos).

3 Universidade Federal de Ciências da Saúde de Porto Alegre (UFCSPA).

4 Universidade Univates.

Address for correspondence: Julia Luiza Schäfer Pontifícia Universidade Católica do Rio Grande do Sul Av. Ipiranga, 6681

90619-900 - Porto Alegre, RS, Brasil

Telephone: (+55 51) 99948-6078

E-mail: julialuizaschafer@gmail.com 


\section{Palavras-chave}

Ideação suicida,

comportamento

adolescente, abuso infantil. drogas também parecem explicar ideação suicida na amostra. Conclusão: Destacamos a importância de futuros estudos longitudinais para investigar os mecanismos por meio dos quais a exposição ao abuso físico ou sexual influencia a ideação suicida em meninos e meninas, bem como estudos de mediação que possam esclarecer o papel do uso de drogas e álcool nessa relação.

\section{INTRODUCTION}

Among many public health problems discussed and faced nowadays, suicide has been one of the main concerns ${ }^{1,2}$. According to the World Health Organization (2012), in 2012, 804,000 people in the world died because of suicide, which accounted for $50 \%$ of male and $71 \%$ of female violent deaths. Globally, suicide is among the three leading causes of death in the 15-44 years old age group, and the second most frequent cause of death in the 15-19 years old age group 3 .

In the years of 1994 to 2004, suicide rates in Brazil were between 3.9 to 4.5 people per 100,000 inhabitants, placing Brazil in the list of countries with the lowest rates. However, due to its numerous population, Brazil was among the first 10 countries with the highest absolute number of suicide occurrences, and some of its states presented rates as high as those in countries displaying medians to high rates ${ }^{4}$. For instance, in the year of 2004, the Brazilian Southern state of Rio Grande do Sul was the one with the highest rate of suicide $^{5-7}$, considering that 9.88 people for every 100,000 inhabitants died from it ${ }^{3}$.

In the last 45 years, a global increase in the occurrence of suicide among youth has been observed ${ }^{4,8}$, supporting data indicating it as one of the main contributors to mortality rates during adolescence ${ }^{9}$. The possibility of young people manifesting suicidal thoughts and behavior grows exponentially after their transition from childhood to adolescence $^{10}$. A systematic review including 128 studies investigating suicide in adolescence reported that $9.7 \%$ of the adolescents in the studies' samples had already tried suicide during their lifetime, and $29.9 \%$ had already thought about it at some point ${ }^{11}$.

The main predictor of self inflicted acts with intention to die, defined as suicidal behaviors, is suicidal ideation, which refers to thoughts of wishes, attitudes and plans about dying $7,10,12,13$. It is estimated that $33.4 \%$ of adolescents having suicidal thoughts develop a suicide plan, and 33,9\% attempt to $i^{14}$, supporting suicidal ideation as one of the most important risk indicators of reaching suicide as an outcome ${ }^{15}$.

The frequency and intensity of suicidal thoughts increase according to age, especially after the first years of adolescence $7,10,14$, and besides contributing to lethal consequences, its occurrence during this developmental stage may produce negative lifetime outcomes ${ }^{15}$. Therefore, comprehending factors related positively and negatively to suicidal ideation allows the development of interventions oriented to the most relevant factors for preventing, identifying and treating suicide.

Socio-demographic and individual factors, as well as adverse family environments and negative experiences during childhood, are considered risk factors for the triggering of suicidal ideation during adolescence ${ }^{16}$. Among the great amount of discussion regarding suicidal behavior and ideation risk and protective factors, some associations stand out. Higher rates of suicide are registered among girls when compared to boys ${ }^{10,12,14}$, among adolescents who are exposed to physical and sexual violence ${ }^{17-19}$, who come from dysfunctional families with histories of psychopathology, and alcohol and drugs abuse $e^{7,9,16}$, and who abuse of alcohol and other drugs ${ }^{12,20,21}$. On the other hand, many studies have suggested that attending to religious institutions, being more exposed to religious beliefs, and paying more importance to religion reduces the chances of suicidal ideation, suicide attempts, and suicide itself22-27.

Available data indicates direct associations between physical and sexual violence, and suicidal thoughts in adolescents ${ }^{11,17,19,28,29}$. Physical and sexual abuse during childhood was found to be strongly associated with suicidal ideation in adolescents even when socio-demographic, mental health, and family variables that could influence this relationship are accounted for ${ }^{17}$. Results from previous studies state that sexual abuse victims show 2 to 3 times more risk of presenting suicidal ideation as a symptom ${ }^{18}$, and that physical abuse is a significant predictor of suicidal ideation also when confounding variables are controlled ${ }^{28,29}$.

Unfortunately, many Brazilian children and adolescents are exposed to violence and abandonment during their lifetime, having to face several types of physical, social, cultural and racial aggression every day ${ }^{30}$. Between 2003 and August 2011, the Brazilian Presidency Human Rights Ombudsmen (Ouvidoria de Direitos Humanos da Presidência da República do Brasil - SDH/PR) received 195,932 complaints about children and adolescents' rights violation at a rate of 209 of these complaints registered every day during January to August $2011^{31}$. Considering the predictive association between exposure to violence and suicidal ideation, comprehending the strength of this relationship in Brazilian samples can aid suicide prevention programs, as well as interventions. Furthermore, considering that Rio 
Grande Sul is the Brazilian state with the highest suicide rates, the present study aims to estimate the association between exposure to physical and sexual violence, and suicidal ideation in southern Brazilian Schoolchildren.

\section{METHODS}

This paper consists of a cross-sectional analytical approach of a larger school-based study. The research was conducted in every school in the cities of Lajeado and Sapiranga, both medium-sized cities located in the countryside of the Brazilian state of Rio Grande do Sul, in the year of 2012.

\section{Participants}

Participants were 3,547 students aging 12 to 17 years old who were randomly selected. Random sampling was carried out by every school's classes, preserving the sample's proportionality by gender, age, sex, and school system (public, or private) in which the adolescents were enrolled.

\section{Procedures}

After both municipalities' departments of education approvals, representatives from each school held the responsibility to make available for the students' guardians the information about the objectives, data collection procedures and ethical implications of the presented study. Special attention was given to the knowledge that the questionnaire used was one of self-report and that the anonymity of those who answered it, as well as those who did not, would be preserved. Informed Consents were distributed and collected by the school before data collection, and the students who did not have the authorization from their guardians, or who did not wish to participate, were instructed to receive the questionnaire and return it blank, therefore avoiding the identification of the non-respondents within the classroom.

Data collection occurred in 214 classrooms in the city of Lajeado, and 75 in the city of Sapiranga. All the students returned the questionnaires to urns especially prepared for this study after filling them out. After the questionnaires were handed in, these urns were sealed and were opened only in a reserved room used for data typing and processing. The students who were unable to answer the questionnaire because of physical, or cognitive deficiency were not asked to participate.

To assure quality, data collection process was assisted in person by trained field supervisors, and all classrooms' visits were scheduled previously. The research projects related to the data collection described were approved by the Ethics Committee of the University of Vale do Rio dos Sinos (Unisinos) prior to execution thereof, under the protocols 074/2011 and 028/2012.

\section{Instruments}

The selected variables for this analytical study were extracted from sociodemographic and dichotomous questions of a questionnaire that was developed for an extensive school-based investigation about the use of psychoactive substances among students, as well as associated conditions. The questionnaire was created based on other studies' instruments $s^{32,33}$ and has been standardized and pre-tested before use.

\section{Data analysis}

Data were entered in the software EpiData 3.5 by double entry for checking and correcting typos. Inconsistencies identification and correction were performed after a first round of analyzes. Altogether, $9.4 \%$ of losses or refusals were computed. Data analysis was conducted using Logistic Regression. Reporting suicidal ideation in the last 30 days (dichotomous, thought about ending his or her life: yes or no) was taken as the outcome variable of this investigation. The exposure variables were life history of any kind of physical or sexual violence (both dichotomous, experience of physical violence in your life: yes or no, or experience of sexual abuse in your life: yes or no). The estimated design effect according to school for the outcome suicidal ideation was 1.48, justifying this effect control in subsequent analysis.

Despite no significant interaction was found between the variable sex and each one of the independent variables reporting life history of violence, neither in multiplicative scale (physical violence: $p=0.689$ and sexual violence: $p$ $=0.330$ ) nor in additive scale (physical violence: $p=0.101$ and sexual violence: $p=0.332$ ), it has been decided to proceed stratified analysis considering specific behaviors of the outcome according to sex. Therefore, two prediction models were tested taking into account some confounding variables. The confounding variables were selected from the literature and were included in the model in an order that considered socio demographic and family context variables, potentially protective factors related to cultural behaviors, or standards, and suicidal ideation identified risk factors beside the proposed exposure variables.

To decide the prediction model of suicidal ideation for boys and girls the confounding variables were tested for associations with the outcome among boys and girls. The potentially confounding variables taken were: age (ordinal categorical: from 12 to 14 years old, and from 15 to 17 years old), responsible guardian education ${ }^{14}$ [ordinal categorical: illiterate or no more than the Elementary School (ES) fourth grade; Between the ES fifth and seventh grade; Complete Elementary School; Complete High School (HS); Complete Higher Education (HE)], religious practice (dichotomous, attend or worship religious practices regularly yes or no) habit of praying (dichotomous, usually pray when having problems yes or no), and use of alcohol, tobacco or illicit 
drugs in the last year (dichotomous, yes or no) and problems with alcohol and drugs at home (dichotomous, yes or no). The confounding variables were only included in the models if the were significantly associated with the outcome suicidal ideation at a $\mathrm{p}<0.002$.

Therefore, the prediction model of suicidal ideation using physical, and sexual abuse as the exposure variables for girls was adjusted for responsible guardian education, religious attendance and praying habit, and use, or family problems with alcohol and other drugs. On the other hand, the same prediction model for boys was adjusted for religious attendance and praying habit, and use, or family problems with alcohol and other drugs.

\section{RESULTS}

The study sample consisted of 3,547 students, $54.2 \%$ of those were female and the mean age was 14 years old ( $s d=1.7$ ).

Table 1. Absolute (n) and relative (\%) sample distribution and Prevalence of Suicidal Ideation (P) according to life history of physical and sexual violence, and other independent variables among schoolgirls, Southern Brazil, $2012(\mathrm{~N}=1924)$

\begin{tabular}{|c|c|c|c|c|}
\hline \multirow[t]{2}{*}{ Variables } & \multicolumn{2}{|c|}{ Sample } & \multicolumn{2}{|c|}{$\begin{array}{l}\text { Suicidal ideation } \\
\text { (last } 30 \text { days) }\end{array}$} \\
\hline & n & $\%$ & $p^{*}$ & PValue \\
\hline Age & & & & 0.212 \\
\hline From 12 to 14 years old & 1197 & $62.2 \%$ & $28.8 \%$ & \\
\hline From 15 to 17 years old & 727 & $37.8 \%$ & $26.1 \%$ & \\
\hline Responsible Guardian Education & & & & 0.007 \\
\hline Elementary or less & 1104 & $59.2 \%$ & $29.9 \%$ & \\
\hline High or Higher education & 762 & $40.8 \%$ & $24.1 \%$ & \\
\hline Problems with alcohol/drugs at home & & & & $<0.001$ \\
\hline No & 1414 & $74.3 \%$ & $23.6 \%$ & \\
\hline Yes & 489 & $25.7 \%$ & $39.6 \%$ & \\
\hline Using of alcohol in the past year & & & & $<0.001$ \\
\hline No & 990 & $51.5 \%$ & $20.7 \%$ & \\
\hline Yes & 934 & $48.5 \%$ & $35.1 \%$ & \\
\hline Using of Tabaco in the past year & & & & $<0.001$ \\
\hline No & 1745 & $90.7 \%$ & $25.0 \%$ & \\
\hline Yes & 179 & $9.3 \%$ & $54.3 \%$ & \\
\hline Using of illicit drugs in the past year & & & & $<0.001$ \\
\hline No & 1709 & $88.8 \%$ & $25.2 \%$ & \\
\hline Yes & 215 & $11.2 \%$ & $47.6 \%$ & \\
\hline Attending to religious activity & & & & $<0.001$ \\
\hline Yes & 1049 & $55.3 \%$ & $24.1 \%$ & \\
\hline No & 848 & $44.7 \%$ & $32.0 \%$ & \\
\hline Praying habit & & & & 0.001 \\
\hline Yes & 1633 & $85.5 \%$ & $26.1 \%$ & \\
\hline No & 277 & $14.5 \%$ & $36.0 \%$ & \\
\hline Exposure to physical abuse & & & & $<0.001$ \\
\hline No & 1669 & $88.0 \%$ & $24.6 \%$ & \\
\hline Yes & 227 & $12.0 \%$ & $52.8 \%$ & \\
\hline Exposure to sexual abuse & & & & $<0.001$ \\
\hline No & 1834 & $96.2 \%$ & $26.6 \%$ & \\
\hline Yes & 72 & $3.8 \%$ & $54.9 \%$ & \\
\hline
\end{tabular}

* Preceded analysis controlling the design effect by the variable school.
From all students, 137 (3.9\%) did not answer the question about suicidal ideation in the last month, therefore, from the 3,410 respondents, 739 [P $=21,7 \%$ (C195\%: 20.3\% - 23.1\%)] reported having thought about ending their own lives during the last 30 days prior to data collection. The absolute and relative sample distributions of this study's interest variables, as well as the prevalence of suicidal ideation according to these variables, are presented in Table 1 for girls and Table 2 for boys.

Among girls, suicidal ideation prevalence was significantly higher among participants whose responsible guardian education was Elementary or less $(p=0.007)$, who have had alcohol, or drug problems at home $(p<0.001)$, who used alcohol ( $p<0.001)$, Tabaco $(p<0.001)$ and illicit drugs $(p<0.001)$ in the past year, who haven't attended any religious practice $(p<0.001)$ and haven't had the habit of praying $(p=0.001)$, as well as those who have been exposed to physical $(p<0.001)$ and sexual abuse $(p<0.001)$. Among boys, suicidal ideation prevalence was significantly higher

Table 2. Absolute (n) and relative (\%) sample distribution and prevalence $(P)$ of suicidal ideation according to life history of physical and sexual violence, and other independent variables among boys, Southern Brazil, $2012(\mathrm{~N}=1623)$

\begin{tabular}{|c|c|c|c|c|}
\hline \multirow[t]{2}{*}{ Variables } & \multicolumn{2}{|c|}{ Sample } & \multicolumn{2}{|c|}{$\begin{array}{c}\text { Suicidal ideation } \\
\text { (last } 30 \text { days) }\end{array}$} \\
\hline & $\mathrm{n}$ & $\%$ & p* & PValue \\
\hline Age & & & & 0.396 \\
\hline From 12 to 14 years old & 992 & $61.1 \%$ & $13.8 \%$ & \\
\hline From 15 to 17 years old & 631 & $38.9 \%$ & $15.3 \%$ & \\
\hline Responsible Guardian Education & & & & 0.591 \\
\hline Elementary or less & 943 & $61.0 \%$ & $15.0 \%$ & \\
\hline High or Higher education & 603 & $39.0 \%$ & $14.0 \%$ & \\
\hline Problems with alcohol/drugs at home & & & & 0.003 \\
\hline No & 1223 & $76.1 \%$ & $13.0 \%$ & \\
\hline Yes & 383 & $23.9 \%$ & $19.2 \%$ & \\
\hline Using of alcohol in the past year & & & & 0.001 \\
\hline No & 919 & $56.6 \%$ & $11.8 \%$ & \\
\hline Yes & 704 & $43.4 \%$ & $17.7 \%$ & \\
\hline Using of Tabaco in the past year & & & & 0.007 \\
\hline No & 1455 & $89.6 \%$ & $13.6 \%$ & \\
\hline Yes & 168 & $10.4 \%$ & $21.5 \%$ & \\
\hline Using of illicit drugs in the past year & & & & $<0.001$ \\
\hline No & 1450 & $89.3 \%$ & $12.5 \%$ & \\
\hline Yes & 173 & $10.7 \%$ & $30.3 \%$ & \\
\hline Attending to religious activity & & & & 0.044 \\
\hline Yes & 767 & $48.2 \%$ & $12.6 \%$ & \\
\hline No & 825 & $51.8 \%$ & $16.2 \%$ & \\
\hline Praying habit & & & & 0.003 \\
\hline Yes & 1164 & $72.4 \%$ & $12.6 \%$ & \\
\hline No & 444 & $27.6 \%$ & $18.4 \%$ & \\
\hline Exposure to physical abuse & & & & $<0.001$ \\
\hline No & 1332 & $83.8 \%$ & $11.7 \%$ & \\
\hline Yes & 258 & $16.2 \%$ & $29.3 \%$ & \\
\hline Exposure to sexual abuse & & & & 0.112 \\
\hline No & 1577 & $98.5 \%$ & $14.3 \%$ & \\
\hline Yes & 24 & $1.5 \%$ & $26.1 \%$ & \\
\hline
\end{tabular}

* Preceded analysis controlling the design effect by the variable school. 
among participants who have had alcohol, or drug problems at home $(p=0.003)$, who used alcohol $(p=0.001)$, Tabaco $(p=0.007)$ and illicit drugs $(p<0.001)$ in the past year, who haven't attended any religious practice $(p=0.044)$ and haven't had the habit of praying ( $p=0.003)$, as well as those who have been exposed to physical abuse ( $p<0.001)$. The variable age was not significantly related to suicidal ideation neither for girls $(p=0.212)$, nor boys $(p=396)$. Besides, for boys, neither responsible guardian education ( $p=0.591$ ), nor exposure to sexual abuse ( $p=0.112$ ) was significantly associated with suicidal ideation.

Results from the regression analysis stratified by sex are presented in Table 3 for girls, and Table 4 for boys. Regression analysis to estimate suicidal ideation prevalence ratios related to exposure to physical or sexual violence in the whole sample are presented in Table 3. Analysis indicated that those girls who have been exposed to physical abuse throughout their lifetime had 3.42 times more probability of referring suicidal ideation in the past 30 days previous to data collection [OR = 3.42 (C195\%: $2.49-4.69), p<0.001$, and those who had been exposed to sexual abuse had 3.36 times more probability of referring suicidal ideation within the same time range [OR $=2.11$ (C195\%: $2.04-5.52), p<$ $0.001]$. When adjusting the analysis to responsible guardian education, and to attendance of any religious practice and praying habit, the odds ratios show subtle alterations for both, physical [OR $=3.13$ (C195\%: $2.19-4.48), p<0.001]$ and sexual abuse exposure [OR $=2.89$ (C195\%: $1.72-4.86] p<$ $0.001]$, suggesting that these variables slightly interfere in the exposure to violence observed effect over the occurrence of suicidal ideation in the past 30 days. On the other hand, when adjusting the analysis to individual, or family problems with alcohol and other drugs, a higher reduction of the odds ratio was perceived among girls who had been exposed to physical [OR $=2.53(C 195 \%: 1.71-3.74), p<0.001]$ and sexual abuse [OR $=2.57$ (Cl95\%: $1.40-4.69), \mathrm{p}<0.001]$.

Among boys, results are very much alike for those who have been exposed to physical violence, suggesting that those boy have 3,14 times more probability of reporting suicidal ideation in the past 30 days previous to data collection $[O R=3.14$ (Cl95\%: $2.45-4.03), p<0.001]$. When adjusting to religious attendance, and praying habit, the odds ration presents a subtle decrease [OR $=3.10$ (C195\%: 2.39 - 4.02), $p<0.001$, while adjusting to use, or family problems with alcohol and other drugs as well shows a more expressive odds ration decrease [OR = 2.83 (C195\%: 2.12 - 3.78), $p<$ $0.001]$. It is important to notice that exposure to sexual abuse was not a significant predictor of suicidal ideation among boys. Results of the adjusted analysis suggest that religious practice might not be a sufficient protective factor against suicidal ideation in the sample, and that part of the effect over suicidal ideation that seemed to be due to the exposure to violence may be explained by individual or family problems with substance use.

Table 3. Odds ratios (OR) and respective confidence intervals of $95 \%$ (IC95\%) for suicidal ideation according to life history of exposure to physical and sexual violence, among 12-17 years old schoolgirls from southern Brazil, $2012(\mathrm{~N}=1924)$

\begin{tabular}{|c|c|c|c|c|c|c|c|c|}
\hline \multirow{2}{*}{$\begin{array}{l}\text { Suicidal ideation among } \\
\text { schoolchildren once } \\
\text { exposed to }\end{array}$} & \multicolumn{2}{|c|}{ Crude analysis* } & \multicolumn{2}{|c|}{$\begin{array}{l}\text { Adjusted to responsible guardian } \\
\text { education* }\end{array}$} & \multicolumn{2}{|c|}{$\begin{array}{l}\text { Adjusted to previous + religious } \\
\text { attendance and praying habit* }\end{array}$} & \multicolumn{2}{|c|}{$\begin{array}{l}\text { Adjusted to previous + use or family } \\
\text { problems with alcohol and other drug** }\end{array}$} \\
\hline & OR & C| $95 \%$ & OR & C| $95 \%$ & OR & C| $95 \%$ & OR & C| $95 \%$ \\
\hline \multicolumn{9}{|l|}{ Physical Violence } \\
\hline No & 1 & & 1 & & 1 & & 1 & \\
\hline Yes & 3.42 & $2.49-4.69^{* *}$ & 3.35 & $2.40-4.67^{* *}$ & 3.13 & $2.19-4.48^{* *}$ & 2.53 & $1.71-3.74^{* *}$ \\
\hline \multicolumn{9}{|l|}{ Sexual Violence } \\
\hline No & 1 & & 1 & & 1 & & 1 & \\
\hline Yes & 3.36 & $2.04-5.52^{* *}$ & 3.12 & $1.91-5.13^{* *}$ & 2.89 & $1.72-4.86^{* *}$ & 2.57 & $1.40-4.69^{* * *}$ \\
\hline
\end{tabular}

* Preceded analysis controlling the design effect by the variable school. ${ }^{* *} p<0.001 .{ }^{* * *} p<0.05$.

Table 4. Odds ratios (OR) and respective confidence intervals of $95 \%$ (IC95\%) for suicidal ideation according to life history of exposure to physical and sexual violence, among 12-17 years old school boys from southern Brazil, 2012 ( $N=1623$ )

\begin{tabular}{|c|c|c|c|c|c|c|}
\hline \multirow{2}{*}{$\begin{array}{c}\text { Suicidal ideation among } \\
\text { schoolchildren once exposed to }\end{array}$} & \multicolumn{2}{|c|}{ Crude analysis* } & \multicolumn{2}{|c|}{ Adjusted to religious attendance and praying habit* } & \multicolumn{2}{|c|}{$\begin{array}{l}\text { Adjusted to previous + use or family problems with } \\
\text { alcohol and other drugs* }\end{array}$} \\
\hline & $O R$ & C $195 \%$ & OR & C|95\% & OR & C $195 \%$ \\
\hline \multicolumn{7}{|l|}{ Physical Violence } \\
\hline No & 1 & & 1 & & 1 & \\
\hline Yes & 3.14 & $2.45-4.03^{* *}$ & 3.10 & $2.39-4.02^{* *}$ & 2.83 & $2.12-3.78^{* *}$ \\
\hline \multicolumn{7}{|l|}{ Sexual Violence } \\
\hline No & 1 & & & & & \\
\hline Yes & 2.11 & $0.79-5.65$ & - & - & - & - \\
\hline
\end{tabular}

* Preceded analysis controlling the design effect by the variable school.

${ }^{* *} p<0.001$. 


\section{DISCUSSION}

Our results show that the prevalence of suicidal ideation in the last month reported by the sample (21.7\%) is consistent ${ }^{11,34}$, and higher ${ }^{12,14,15}$ than results already found in community and school based samples of adolescents between 11 and 20 years old. Altogether, these data support the increased possibility, already reported ${ }^{10}$, of young people manifesting suicidal thoughts after their transition from childhood to adolescence.

The main purpose of this study was to estimate the association between exposure to physical, or sexual violence, and suicidal ideation in a Brazilian adolescent school based sample. Results from crude analysis stratified by sex point out to a significant association, in which girls who have been physically and sexually abused present, respectively, 3.42 and 3.36 more probability of reporting suicidal ideation in the last month, and boys who have been exposed to physical abuse present 2.11 more probability of reporting the same outcome. These findings are somewhat consistent with what is found in the literature suggesting that physical28,29 abuse is an important predictor of suicidal ideation among female and male, and that sexual abuse ${ }^{35}$ is an important predictor of suicidal behavior among girls.

These results express differences between type of abuse exposure between boys and girls with higher prevalence of sexual abuse among girls, and higher prevalence of physical abuse among boys. For this sample, sexual abuse was not a significant predictor of suicidal ideation among boys, even though the prevalence of the outcome was higher among those boys who had been exposed to sexual abuse. Exposure to both types of abuse has already been associated with higher risk for mental disorders, including suicidal ideation, between 16 and 25 years old ${ }^{36}$ of both sexes. It is believed that because of the few occurrences of sexual abuse among boys, no associations with the outcome were possible to be estimated precisely.

Even though the association between exposure to abusive experiences and suicidal ideation is already established in the literature, little is know about the mechanisms through which these experiences lead to suicidal behavior. From a neurodevelopmental perspective, these experiences carry the potential to cause disruptions and neurological scars because, in order to deal with highly stressful environments during development, individuals have to modify the psychological and neurological structure and function to adapt to these environments. The result of these disruptions and adaptations is what makes individuals more prone to developing certain types of psychopathology and symptoms ${ }^{37}$. Besides, these experiences generate intense stress reactions that, when repeated, lead individuals to become chronically stressed and overly vigilant, presenting an atypical cortisol regulation ${ }^{35}$. Even though there is data regarding the impact of repeated exposure to abusive experiences on healthy development, this study did not collect detailed data about the sample's frequency of exposure to physical or sexual abuse.

Moreover, it is suggested that painful and provocative experiences, such as abusive ones, confer increased risk for suicidal behavior through emotional states of burdensomeness and disconnection ${ }^{38}$. Such experiences may drive children and adolescents to hopelessness, or in other words, to a negative cognitive system of beliefs and expectations about the future. Hopelessness, by its turn, has already been associated with suicidal ideation, as well as connected with children maltreatment ${ }^{39}$.

Because exposure to violence is only one among many factors that might contribute to suicidal behavior or ideation in adolescents ${ }^{11}$, socio-demographic, religiosity, and drug use confounding variables were included in the analyses to examine their effect over this relationship. The sociodemographic variable of guardian education among girls, as well as religious attendance and praying habit among girls and boys had very subtle effects over the mentioned relationship. On the contrary, use of alcohol and drugs by family or by the adolescent considerably reduced the probability of reporting suicidal ideation among those adolescents physically, or sexually abused suggesting that those kind of problems might increase the risk of suicidal ideation among the adolescents who hadn't been exposed to physical and sexual abuse.

Differently than what was expected, religious practice and the habit of praying slightly influenced the magnitude of the relationship between exposure to physical and sexual abuse and suicidal ideation, as it is suggested by the comparisons of the crude and adjusted analyses confidence intervals and the estimated prevalence ratios shown on Table 3. Even though a small reduction in the estimated odds ration is observed when religious attendance and praying habit are included, a more expressive decrease is only seen when use or family problems with alcohol and other drugs are included in the model. One of the possible reasons for that is that religiosity variables may have a protective effect over suicide attempts, which was not evaluated in this study, but not suicidal ideation. Rates of suicidal attempts have already been shown to be lower in religious groups when compared to non-religious groups, while suicidal ideation rates remained similar ${ }^{40}$.

On the other hand, the individual or family problems with alcohol and other drugs effect observed over the already mentioned relationship suggests that part of the effect previously thought to be from exposure to physical or sexual violence over suicidal ideation may be due to individual or family use of alcohol and other drugs. It is already documented that levels of alcohol and other drugs use show increases with adolescents exposure to violence ${ }^{41}$. 
Even though both conditions show predictive effects of suicidal ideation, the question of whether use of alcohol and drugs increases exposure to violence, or exposure to violence increases use of alcohol and drugs remains. Besides, parental use of alcohol and drugs has already been investigated as a moderator of the relationship between exposure to physical and sexual assault and psychiatric functioning, including major depressive episodes and adolescent substance use $\mathrm{e}^{42}$. When testing for depressive episodes and adolescent use of substances as outcomes, significant interactions were found between parental substance use and physical and sexual assault, suggesting that parental alcohol and drug abuse may intensify the risk of poor psychological outcomes, such as suicidal ideation, for violence-exposed adolescents ${ }^{42}$. Further research is warranted to understand the direction of the relationship between adolescents substance use and exposure to violence, and whether parental drug use may lead to more violence exposure, and it is this violence exposure that leads to adverse outcomes.

Additionally, based on current evidence, family substance use is associated with suicidal ideation ${ }^{16}$, as well as lifetime substance use is associated with suicidal ideation ${ }^{43-45}$ and sexual abuse. In fact, substance use can be, at the same time, a consequence of sexual abuse, and a risk factor for suicidal behavior ${ }^{18}$. This type of behavior is significantly more common among drug users than in the general population, and sexual, physical, and emotional abuse confer important risk of repeated suicidal behavior within this population ${ }^{44}$.

The results of this study should be interpreted with caution because some of its limitations. Because of the study cross sectional design, no casual, mediated, or moderated relationships can be established among the variables. At the same time, the results cannot be generalized due to the sample's non-representative characteristics. It is know that suicidal behavior is a multifactorial phenomenon with many psychological, social, biological, and environmental variables that may contribute to its occurrence ${ }^{9}$, and not all of them could be controlled in the present study. For instance, since it was not the scope of this article, psychopathology levels were not controlled and accounted for, even though they might influence suicidal behavior.

It is also important to consider that the only source of information about exposure to physical or sexual abuse was the adolescents who participated and answered a selfreport questionnaire investigating the interest variables through "yes" or "no" questions. Every individual is subjected to memory distortions, either through the creation of false memories, or through the sub estimation of violent experiences caused by difficulties in comprehending, or recognizing violent actions. Moreover, subjective reports of abuse may be influenced by inconsistencies in what defines physical or sexual abuse, what means that individuals can have different comprehensions, or thresholds, for what they consider abusive experiences ${ }^{43}$. Additionally, even though it is known that there are many variables related to the exposure to adverse events that may impact levels of psychiatric symptoms, it was not possible to collect information about the frequency, duration, or age of the exposure to these events, as well as information about who was the aggressor.

Furthermore, the severity of these experiences was not possible to be controlled, even though its influence on different negative consequences is already reported ${ }^{38}$. In the analyses, physical and sexual abuse were not independently analyzed, so this study is unable to suggest which form of abuse can be more important for suicidal ideation occurrence. There is evidence that only sexual, but not physical abuse, is associated with suicidal behavior ${ }^{35}$ at the same time as there is evidence that both types of abuse can predict suicidal behavior ${ }^{16,46}$.

Finally, we highlight the importance of future longitudinal studies to investigate the mechanisms through which exposure to physical, or sexual abuse influence suicidal ideation differently among girls and boys, as well as mediation, or moderation studies that could enlighten the role of drug and alcohol use, and other variables, in this relationship. We also suggest that future studies evaluate severity of exposure to physical and sexual abuse, and investigate their prediction of suicidal ideation independently.

\section{INDIVIDUAL CONTRIBUTIONS}

Julia Luiza Schäfer - Participated in data collection, literature review, organization of the databases, statistical analysis and interpretation of the results.

Vanessa Andina Teixeira - Participated in the statistical analysis and interpretation of the results.

Larissa Prado da Fontoura - Participated in the design and planning of the study.

Luís César de Castro - Participated in the design and planning of the study.

Rogério Lessa Horta - Participated in the design and planning of the study, statistical analysis and interpretation of the results, as well as data collection, literature review and organization of the databases.

All authors participated in the drafting and approval of the final version of the manuscript.

\section{FINANCIAL DISCLOSURES}

This research did not receive any specific grant from funding agencies in the public, commercial, or not-for-profit sectors.

\section{CONFLICTS OF INTEREST}

The authors declare no conflict of interest. 


\section{REFERENCES}

1. Swahn MH, Bossarte RM. Gender, early alcohol use, and suicide ideation and attempts: findings from the 2005 youth risk behavior survey. J Adolesc Health. 2007;41(2): $175-81$.

2. Barbosa LP, Quevedo L, da Silva Gdel G, Jansen K, Pinheiro RT, Branco J, et al. Childhood trauma and suicide risk in a sample of young individuals aged 14-35 years in southern Brazil. Child Abuse Negl. 2014;38(7):1191-6.

3. World Health Organization. Public health action for the prevention of suicide: a framework. Geneva, 2012.

4. Ministério da Saúde (Brasil). Prevenção do suicídio. Manual dirigido a profissionais das equipes de saúde mental. Universidade Estadual de Campinas, 2006

5. Lovisi GM, Santos SA, Legay L, Abelha L, Valencia E. Análise epidemiológica do suicídio no Brasil entre 1980 e 2006. Rev Bras Psiquiatr. 2009;31(Supl II):S86-93.

6. Meneghel SN, Victora CG, Faria NMX, Carvalho LA, Falk JW. Características epidemiológicas do suicídio no Rio Grande do Sul. Rev Saude Publica. 2004;38(6):804-10.

7. Borges VR, Werlang BSG. Estudo de ideação suicida em adolescentes de 15 a 19 anos. Estud Psicol. 2006;11(3):345-51.

8. Bertolote JM, Mello-Santos C, Botega NJ. Detecção do risco de suicídio nos serviços de emergência psiquiátrica. Rev Bras Psiquiatr. 2010;32:S87-95.

9. Hagedorn J, Omar H. Retrospective analysis of youth evaluated for suicide attempt or suicidal ideation in an emergency room setting. Int J Adolesc Med Health. 2002;14(1):55-60.

10. Adrian M, Miller AB, McCauley E, Vander Stoep A. Suicidal ideation in early to middle adolescence: sex-specific trajectories and predictors. J Child Psychol Psychiatry. 2016;57(5):645-53

11. Evans E, Hawton K, Rodham K. Suicidal phenomena and abuse in adolescents: a review of epidemiological studies. Child Abus Negl. 2005;29(1):45-58.

12. Sampasa-Kanyinga H, Dupuis LC, Ray R. Prevalence and correlates of suicidal ideation and attempts among children and adolescents. Int J Adolesc Med Health. 2017;29(2).

13. Kapczinski F, Quevedo J. Transtorno Bipolar: Teoria e clínica. Porto Alegre: Artmed; 2009.

14. Nock MK, Green JG, Hwang I, McLaughlin KA, Sampson NA, Zaslavsky AM, et al. Prevalence, correlates, and treatment of lifetime suicidal behavior among adolescents: results from the National Comorbidity Survey Replication Adolescent Supplement. JAMA Psychiatry. 2013;70(3):300-10.

15. Souza LDM, Silva RA, Jansen K, Kuhn RP, Horta BL, Pinheiro RT. Suicidal ideation in adolescents aged 11 to 15 years: prevalence and associated factors. Rev Bras Psiquiatr. 2010;32(1):37-41.

16. Waldrop AE, Hanson RF, Resnick HS, Kilpatrick DG, Naugle AE, Saunders BE. Risk factors for suicidal behavior among a national sample of adolescents: implications for prevention. J Trauma Stress. 2007;20(5):869-79.

17. Miller AB, Esposito-Smythers C, Weismoore JT, Renshaw KD. The relation between child maltreatment and adolescent suicidal behavior: A systematic review and critical examination of the literature. Clin Child Fam Psychol Rev. 2013;16(2):146-72.

18. Pérez-González A, Pereda N. Systematic review of the prevalence of suicidal ideation and behavior in minors who have been sexually abused. Actas Esp Psiquiatr. 2015;43(4):149-58.

19. Thompson R, Proctor LJ, English DJ, Dubowitz H, Narasimhan S, Everson MD. Suicidal ideation in adolescence: examining the role of recent adverse experiences. J Adolesc. 2012;35(1):175-86

20. Gart R, Kelly S. How illegal drug use, alcohol use, tobacco use, and depressive symptoms affect adolescent suicidal ideation: a secondary analysis of the 2011 youth risk behavior survey. Issues Ment Health Nurs. 2015;36(8):614-20.

21. Peltzer K, Pengpid S. Early substance use initiation and suicide ideation and attempts among school-aged adolescents in four pacific island countries in Oceania. Int J Environ Res Public Health. 2015;12(10):12291-303.

22. Moreira-Almeida A, Lotufo-Neto F, Koenig HG. Religiousness and mental health: a review. Rev Bras Psiquiatr. 2006;28(919):242-50

23. Stack S, Lester D. The effect of religion on suicide ideation. Soc Psychiatry Psychiatr Epidemiol. 1991;26(4):168-70.
24. Rasic DT, Belik SL, Elias B, Katz LY, Enns M, Sareen J; Swampy Cree Suicide Prevention Team. Spirituality, religion and suicidal behavior in a nationally representative sample. J Affect Disord. 2009;114(1-3):32-40.

25. Talib MA, Abdollahi A. Spirituality moderates hopelessness, depression, and suicidal behavior among Malaysian adolescents. J Relig Health. 2017;56(3):784-95.

26. Rasic D, Kisely S, Langille DB. Protective associations of importance of religion and frequency of service attendance with depression risk, suicidal behaviours and substance use in adolescents in Nova Scotia, Canada. J Affect Disord. 2011;132(3):389-95.

27. Caribé AC, Nunez R, Montal D, Ribeiro L, Sarmento S, Quarantini LC, et al. Religiosity as a protective factor in suicidal behavior: a case-control study. J Nerv Ment Dis. 2012;200(10):863-7.

28. Fuller-Thomson E, Baker TM, Brennenstuhl S. Evidence supporting an independent association between childhood physical abuse and lifetime suicidal ideation. Suicide Life Threat Behav. 2012;42(3):279-91.

29. Salzinger S, Rosario M, Feldman RS, Ng-Mak DS. Adolescent suicidal behavior: associations with preadolescent physical abuse and selected risk and protective factors. J Am Acad Child Adolesc Psychiatry. J Am Acad Child Adolesc Psychiatry. 2007:46(7):859-66.

30. Zem-mascarenhas SH, Dupas G. Institutionalized children and their experiences. Rev Esc Enferm. 2001;35(4):413-9.

31. Brasil. Relatório disque direitos humanos: módulo criança e adolescente. Brasília; 2011.

32. Carlini EA, Sanchez ZM, Carlini CMA, et al. VI levantamento nacional sobre o consumo de drogas psicotrópicas entre estudantes do ensino fundamental e médio das redes públicas e privadas de ensino nas 27 capitais brasileiras. São Paulo; 2010

33. Galduróz JCF, Noto AR, Fonseca AM, Carlini EA. V levantamento nacional sobre o consumo de drogas psicotrópicas entre estudantes do ensino fundamental e médio da rede pública de ensino nas 27 capitais brasileiras. São Paulo; 2004.

34. Evans E, Hawton K, Rodham K, Deeks J. The prevalence of suicidal phenomena in adolescents: a systematic review of population-based studies. Suicide Life Threat Behav. 2005:35(3):239-50

35. Lopez-Castroman J, Melhem N, Birmaher B, Greenhill L, Kolko D, Stanley B, et al. Early childhood sexual abuse increases suicidal intent. World Psychiatry. 2013;12(2):149-54.

36. Fergusson D, Boden J, Horwood J. Exposure to childhood sexual and physical abuse and adjustment in early adulthood. Child Abus Negl. 2008;32(6):607-19.

37. Grassi-Oliveira R, Ashy M, Stein LM. Psychobiology of childhood maltreatment: Effects of allostatic load? Rev Bras Psiquiatr. 2008;30(1):60-8.

38. Joiner TE Jr, Sachs-Ericsson NJ, Wingate LR, Brown JS, Anestis MD, Selby EA. Childhood physical and sexual abuse and lifetime number of suicide attempts: A persistent and theoretically important relationship. Behav Res Ther. 2007:45(3):539-47.

39. Turner HA, Finkelhor D, Shattuck A, Hamby S. Recent victimization exposure and suicidal ideation in adolescents. Arch Pediatr Adolesc Med. 2012;166(12):1149-54.

40. Burshtein S, Dohrenwend BP, Levav I, Werbeloff N, Davidson M, Weiser M. Religiosity as a protective factor against suicidal behaviour. Acta Psychiatr Scand. 2016;133(6):481-8.

41. Vermeiren R, Schwab-Stone M, Deboutte D, Leckman PE, Ruchkin V. Violence exposure and substance use in adolescents: findings from three countries. Pediatrics. 2003;111(3):535-40.

42. Hanson RF, Self-Brown S, Fricker-Elhai A, Kilpatrick DG, Saunders BE, Resnick H. Relations among parental substance use, violence exposure and mental health: the national survey of adolescents. Addictive behaviors. 2006:31(11):1988-2001.

43. Poorolajal J, Haghtalab T, Farhadi M, Darvishi N. Substance use disorder and risk of suicidal ideation, suicide attempt and suicide death: a meta-analysis. J Public Health (0xf). 2016;38(3):e282-e291.

44. Marshall BDL, Galea S, Wood E, Kerr T. Longitudinal associations between types of childhood trauma and suicidal behavior among substance users: A cohort study. Am J Public Health. 2013;103(9):e69-75.

45. Lloyd JJ, Ricketts EP, Havens JR, Cornelius LJ, Bishai D, Huettner S, et al. The relationship between lifetime abuse and suicidal ideation in a sample of injection drug users. J Psychoactive Drugs. 2007;39(2):159-66.

46. Ystgaard M, Hestetun I, Loeb M, Mehlum L. Is there a specific relationship between childhood sexual and physical abuse and repeated suicidal behavior? Child Abuse Negl. 2004;28(8):863-7. 